\title{
Phellinus linteus sensitises apoptosis induced by doxorubicin in prostate cancer
}

\author{
L Collins ${ }^{1,3}$, T Zhu' ${ }^{1,3}$, J Guo', ZJ Xiao ${ }^{2}$ and C-Y Chen ${ }^{*, 1}$ \\ 'Department of Pathology, K522, Boston University School of Medicine, 80 East Concord Street, Boston, MA 021 I 8, USA; ${ }^{2}$ Department of Biochemistry, \\ Boston University School of Medicine, 80 East Concord Street, Boston, MA 02118, USA
}

It has been demonstrated that the Phellinus linteus (PL) mushroom, which mainly consists of polysaccharides, possesses antitumour activity. The mechanisms of PL against malignant growth remain unknown. The anticancer drug doxorubicin (Dox) has been shown to induce apoptosis via initiating a caspase cascade. In this investigation, we tested the effect of PL on Dox-induced apoptosis in prostate cancer LNCaP cells. We showed that PL or Dox, at relatively low doses, does not induce apoptosis in the cells. However, combination treatment with low doses of PL and Dox results in a synergistic effect on the induction of apoptosis. In this apoptotic process, caspases 8, 3 and BID are cleaved, and the addition of caspase inhibitor z-VADfmk completely blocks apoptosis. In addition, JNK is activated in response to PL or the combination treatment in LNCaP cells. The suppression of JNK partially inhibits the induction of apoptosis elicited by the co-treatment. These findings indicate that PL has a synergistic effect with Dox to activate caspases in prostate cancer LNCaP cells. Our study also suggests that PL has therapeutic potential to augment the magnitude of apoptosis induced by antiprostate cancer drugs.

British Journal of Cancer (2006) 95, 282-288. doi: I 0.1038/sj.bjc.6603277 www.bjcancer.com

Published online 25 July 2006

(c) 2006 Cancer Research UK

Keywords: Phellinus linteus; doxorubicin; apoptosis; caspase; prostate cancer

A major challenge in the treatment of prostate cancer, especially the hormonally refractory form, is the presence of genetic and cellular abnormalities associated with tumorigenesis. Therefore, development of less toxic, more effective treatments is necessary. One strategy is to explore and understand the mechanisms of action of natural medicines. Fungi, like yeast, algae, bacteria and higher plants have been intensively investigated for antitumour modality, because it appears that they are able to modulate the body's immune responses against tumours with very low toxic potential (Oh et al, 1992; Song et al, 1995; Borchers et al, 1999; Han et al, 1999). Studies indicate that the main components in these basidiomycetes are polysaccharides (Lorenzen and Anke, 1998; Reshetnikov et al, 2001; Wasser, 2002). Beta-glucocans isolated from lentinan (Lentinus edodes), pachymaran (Poria cocos), schizophyllan (Schizophyllum commune) and krestin (Coriolus versicolor) have been demonstrated to stimulate lymphocytes and elicit nonspecific immune-activities in various experimental settings (Wasser, 2002). It has also been reported that Phellinus linteus (PL) has the most potent effect among basidiomycetes in antitumour action (Wasser, 2002). Studies have also shown that PL extraction is able to strongly suppress the growth of various tumours in vitro and in vivo (Chihara et al, 1969; Chung et al, 1982; Cun et al, 1994), including the induction of growth arrest or

\footnotetext{
*Correspondence: Associate Professor C-Y Chen;

E-mail: yanyan@bu.edu

${ }^{3}$ These authors contributed equally to the work

Revised 12 June 2006; accepted 20 June 2006; published online 25 July 2006
}

apoptosis. However, the molecular signalling involved in PLmediated antitumour activity has not yet been fully explored.

Caspases are key apoptotic effectors and belong to a family of cysteine-containing, aspartate-specific proteases (Alnemri et al, 1996; Nicholson and Thomberry, 1997). Caspases exist as dormant proenzymes in cells and are activated through proteolysis. Once activated, caspases cleave a host of cellular substrates, leading to morphological hallmarks of apoptosis, including DNA fragmentation. In a caspase cascade, caspase 8 or 9 acts as the initiator, whereas others (e.g., caspases 3 and 7) serve as effectors of apoptosis (Cohen, 1997; Salvesen and Dixit, 1997). Several anticancer drugs, such as doxorubicin (Dox), have been suggested to elicit a caspase cascade, leading to apoptosis (Hannun, 1997; Los et al, 1997). A low dose of Dox can activate the $G_{1}$ checkpoint via a p53-dependent pathway, and high doses of Dox cause apoptosis (Hannun, 1997; Los et al, 1997). Studies have also shown that Dox can synergise with other drugs to induce cytotoxic effects against breast cancer, hepatocellular carcinoma and colon carcinoma (Keane et al, 1999; Muzutani et al, 1999; Yamanaka et al, 2000; Lacour et al, 2001). The combination treatment of Dox and TRAIL dramatically augments the therapeutic effect against prostate cancer (Wu et al, 2002).

JNK, a c-Jun $\mathrm{NH}_{2}$-terminal kinase, was discovered to bind to the c-Jun transactivation domain and phosphorylate Ser-63, Ser-73 and some secondary sites (Devary et al, 1991; Hibi et al, 1993). JNK is rapidly phosphorylated and subsequently activated in response to various stimuli, including different types of stresses (Devary et al, 1991; Hibi et al, 1993). Studies have shown that JNK can promote apoptosis by regulating BID processing or $\mathrm{C}-\mathrm{FLIP}_{\mathrm{L}}$ 
degradation (Derijard et al, 1994; Davis, 2000). Upon activation, JNK phosphorylates Itch (a E3-related ligase) and accelerates the decay of $\mathrm{c}-\mathrm{FLIP}_{\mathrm{L}}$, which augments caspase 8 activity and allows apoptosis to proceed (Gao et al, 2004; Chang et al, 2006).

Based on the information that Dox can synergise with TRAIL to elicit cytotoxicity in various types of tumours (Hannun, 1997; Los et al, 1997; Keane et al, 1999; Muzutani et al, 1999; Yamanaka et al, 2000; Lacour et al, 2001; Wu et al, 2002) as well as that PL is able to interfere with tumour growth, we tried to explore the potential of the combination treatment of Dox and PL against prostate cancer. We examined LNCaP prostate cancer cells looking for evidence of synergy between Dox and PL, and specifically to identify the molecular mechanisms underlying this synergistic effect. In the cells tested, PL enhanced Dox-induced cell death, possibly via caspase-mediated apoptotic signalling pathways. During this process, caspases 8,3 and BID were activated by the combination treatment of low doses of PL and Dox. The apoptotic process could be blocked by the addition of caspase inhibitor z-VADfmk. Phellinus linteus itself could also upregulate JNK activity and

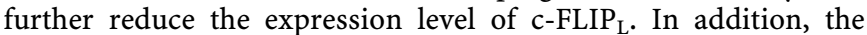
suppression of JNK partially blocked apoptosis induced by the combination treatment of PL and Dox. The data suggest that PL may act through interfering with antiapoptotic factor c-FLIP $\mathrm{L}_{\mathrm{L}}$ to sensitise Dox-mediated apoptotic signalling. Our study also implies that the combination of PL and Dox may have potential for the development of a more effective treatment against prostate cancer.

\section{MATERIALS AND METHODS}

\section{Cell culture and treatments}

The human prostate cancer LNCaP cells were purchased from American Tissue Culture Collection (Rockville, MD, USA) and cultured in Dulbecco's modified Eagle's medium (DMEM) supplemented with $10 \%$ heat-inactivated fetal calf serum (FCS) $2 \mathrm{~mm}$ L-glutamine, $100 \mathrm{U} \mathrm{ml}^{-1}$ of penicillin, $100 \mathrm{~g} \mathrm{ml}^{-1}$ of streptomycin. Normal human prostate epithelial PrEC cells (Cambrex, One Meadowlands Plaza, East Rutherford, NJ, USA) were cultured in the PrEGM medium (Cambrex, NJ, USA). Whole powdered PL that had been grown on germinated brown rice was purchased from Panbio-Tech (Taejon, Korea), and purified using ethanol precipitation methods, followed by DEAE-cellulose and gel permeation chromatography (Song et al, 1995). The purified components of PL mostly consist of polysacharides. Doxorubicin was purchased from Sigma, St Louis, MO, USA.

\section{Flow cytometric determination of nuclear DNA fragmentation assay}

A flow cytometric analysis was performed with a FACScan (Becton-Dickenson, Mountain View, CA, USA). The data analysis and display were performed using the Cell-Fit software program (Becton-Dickenson). Cell-Fit interprets data from the flow cytometer and provides real-time statistical analysis of the data, computed at $1 \mathrm{~s}$ intervals and also discriminates doublets or adjacent particles. Briefly, following various treatments, cells $\left(1 \times 10^{6} \mathrm{ml}^{-1}\right)$ were washed with $1 \times$ phosphate-buffered saline (PBS), fixed with $70 \%$ ethanol, and treated with $10 \mathrm{ng} \mathrm{ml}^{-1}$ RNAse. Subsequently, cells were stained with propidium iodide $\left(5 \mu \mathrm{g} \mathrm{ml}^{-1}\right)$. The stained samples were kept in the dark at $4{ }^{\circ} \mathrm{C}$ overnight before flow cytometric analysis.

\section{$\left[{ }^{3} \mathrm{H}\right]$ Thymidine incorporation assay}

After treatment, cells growing in 24-well plates were starved for $48 \mathrm{~h}$. The growth medium containing $\left[{ }^{3} \mathrm{H}\right]$ thymidine $\left(2 \mu \mathrm{Ci} \mathrm{ml}^{-1}\right)$ was then added, with or without treatment. Twenty-four hours later, the medium was aspirated and cells were fixed. After washing with $1 \mathrm{ml}$ of $5 \%$ trichloroacetic acid, cells were solubilised in $1 \%$ sodium dodecyl sulphate (SDS) and $0.3 \mathrm{~nm} \mathrm{NaOH}$. Incorporated radioactivity was determined by scintillation counter.

\section{Immunoblot}

After treatment, cells were washed in $1 \times$ PBS and then lysed in the lysis buffer (50 mM Tris- $\mathrm{HCl}, \mathrm{pH} 8.0,150 \mathrm{~mm} \mathrm{NaCl}, 1 \%$ Triton X$114,0.5 \%$ sodium deoxycholate, $0.1 \%$ SDS, containing $1 \mathrm{~mm}$ phenylmethylsulphonyl fluoride, $1 \mu \mathrm{g} \mathrm{ml}^{-1}$ aprotinin, $1 \mu \mathrm{g} \mathrm{ml}^{-1}$ leupeptin, $1 \mu \mathrm{g} \mathrm{ml}^{-1}$ pepstatin A) on ice for $30 \mathrm{~min}$. The total protein concentrations in the cell lysates were normalised and adjusted to $0.4 \mathrm{M} \mathrm{NaCl}, 0.5 \%$ deoxycholate and $0.05 \%$ SDS for immunoblotting (Denis et al, 2003). The samples were separated on a $10 \%$ SDS-polyacrylamide gel electrophoresis gel and subsequently transferred to a nitrocellulose membrane. All the antibodies used were purchased from BD Biosciences (San Diego, CA, USA).

\section{Caspase activity assay}

After various treatments, lysates were prepared and the activities of caspases 3 and 8 were measured by a colorimetric analysis ( $\mathrm{Wu}$ et al, 2001).

\section{Preparation of subcellular fractions}

After the treatments, cells $\left(1 \times 10^{7}\right)$ were washed twice with $1 \times$ PBS and resuspended in $1 \mathrm{ml}$ of $1 \%$ Triton X-114 lysis buffer (Denis et al, 2003). The cell suspensions were transferred to a 1-ml syringe and sheared by being passed 40 times through a $25-\mathrm{G}$ needle. The lysates were centrifuged at $280 \mathrm{~g}$ for $10 \mathrm{~min}$, and the supernatant was centrifuged at $16000 \mathrm{~g}$ for $30 \mathrm{~min}$. Afterwards, the supernatant was collected as the cytosolic fraction. For the mitochondrial fraction, the cells $\left(1 \times 10^{9}\right)$ were resuspended in buffer A (50 mM Tris, $\mathrm{pH} 7.5,1 \mathrm{~mm}$ ethyleneglycol tetraacetate, $5 \mathrm{~mm}$ 2-mercaptoethanol, $0.2 \%$ bovine serum albumin, $10 \mathrm{~mm}$ $\mathrm{KH}_{2} \mathrm{PO}_{4}, \mathrm{pH}$ 7.6, $0.4 \mathrm{M}$ sucrose), and allowed to swell on ice for $40 \mathrm{~min}$. After centrifugation, the resulting pellets were resuspended in buffer B ( $10 \mathrm{mM} \mathrm{KH}_{2} \mathrm{PO}_{4}, \mathrm{pH} 7.2,0.3 \mathrm{~mm}$ mannitol, $0.1 \%$ bovine serum albumin). The mitochondrial fractions were subsequently separated on a sucrose step gradient (Denis et al, 2003).

\section{Soft agar assay}

Petri dishes were first layered with $0.6 \%$ basal agar dissolved in DMEM medium containing $10 \%$ FCS. Cells were mixed in $0.33 \%$ agar dissolved in DMEM medium containing PL $\left(1 \mathrm{mg} \mathrm{ml}^{-1}\right)$. The plates were incubated at $37^{\circ} \mathrm{C}$ in a humidified atmosphere for 14 days. Fresh medium $(2 \mathrm{ml})$ containing PL $\left(1 \mathrm{mg} \mathrm{ml}^{-1}\right)$ was added to the cultures every 3 days.

\section{RESULTS}

PL mushroom and doxorubicin, at a low dose, synergise to induce apoptosis in prostate cancer cells

It is known that PL can interfere with tumour proliferation, and the antitumour effect of PL has been indicated to be related to the contents of polysacharides (Chihara et al, 1969; Chung et al, 1982; Cun et al, 1994). However, the mechanisms of PL that suppress tumour growth remain unknown. To further investigate the antitumour effect of PL in prostate cancer, we tested the effect of the combination treatment of PL and Dox, at a low dose range, on human prostate cancer LNCaP cells that have been shown to be sensitive to Dox treatment (Hannun, 1997; Los et al, 1997; Keane et al, 1999; Muzutani et al, 1999; Yamanaka et al, 2000; Lacour 


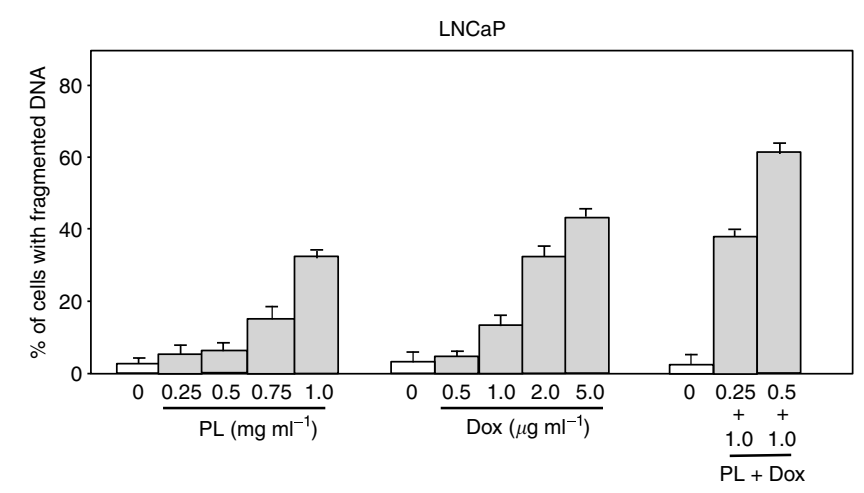

Figure I DNA fragmentation and $\left[{ }^{3} \mathrm{H}\right]$ thymidine incorporation in response to the treatment of $\mathrm{PL}$, Dox and $\mathrm{PL}$ plus Dox. $(\mathbf{A})$ and $(\mathbf{B})$ $\mathrm{LNCaP}$ or PrEC cells were cultured in the growth medium in the presence of different concentrations of PL, Dox, or PL plus Dox. After treatment for $48 \mathrm{~h}$, the percentage of cells with fragmented DNA was analysed by a flow cytometer. Error bars represent the s.d. over five independent experiments. (C) Following serum-starvation ( $0.5 \%$ serum) for $48 \mathrm{~h}$, the cells were refed with growth medium containing $10 \%$ serum and $\left[{ }^{3} \mathrm{H}\right]$ thymidine $\left(2 \mu \mathrm{Ciml}^{-1}\right)$ in the presence or absence of $\mathrm{PL}$, Dox or both for $24 \mathrm{~h}$. Subsequently, trichloroacetic acid-insoluble radioactivity was determined. Error bars represent the s.d. from five independent experiments.

et al, 2001; Wu et al, 2002). LNCaP cells were either left untreated, or treated with different doses of PL, Dox or the combination of these two for $48 \mathrm{~h}$. Afterwards, a DNA fragmentation assay was conducted (Figure 1A). Under normal growth conditions, only a few untreated LNCaP cells had fragmented DNA. After treatment with PL alone, the percentage of DNA fragmentation was moderately increased in a dose-dependent manner. A similar phenomenon was observed following Dox treatment; low doses of Dox had a minor apoptotic effect on the cells. In comparison, treatment with high doses of Dox $\left(>2 \mu \mathrm{g} \mathrm{ml}^{-1}\right)$ for $24 \mathrm{~h}$ caused more than $40 \%$ of the cells to have fragmented DNA, also in a dose-dependent manner. As low doses of PL or Dox could not induce apoptosis, we tested whether the combination of these two would affect cell viability. The cells were treated with 0.25 or $0.5 \mathrm{mg} \mathrm{ml}^{-1}$ of PL plus $1 \mu \mathrm{g} \mathrm{ml}^{-1}$ of Dox. Twenty-four hours after the combination treatment, the percentage of DNA fragmentation was analysed. A significant synergy of PL and Dox in the induction of apoptosis was observed. Normal prostate epithelial PrEC cells were also used for testing the synergistic effect on the induction of apoptosis (Figure 1B). Neither the drug alone nor the combination treatment elicited apoptosis in the normal cells. To further define the growth pattern of PrEC cells in response to the combination treatment, a $\left[{ }^{3} \mathrm{H}\right]$ thymidine incorporation assay was performed (Figure 1C). Serum-starved PrEC cells incorporated a large amount of $\left[{ }^{3} \mathrm{H}\right]$ thymidine into their genome after adding the growth medium containing $10 \%$ serum. In contrast, cells under the same growth conditions did not incorporate $\left[{ }^{3} \mathrm{H}\right]$ thymidine in response to the treatment of PL, Dox or both. Overall, the results indicate that PL, at low doses, can render the prostate cancer cells, but not the normal prostate epithelial cells, susceptible to Dox-induced apoptosis.

To further define the long-term effect of the combination treatment of PL and Dox on tumour growth, a soft agar assay was performed (Table 1). Untreated LNCaP cells formed colonies in soft agar medium. Interestingly, although low doses of PL or Dox did not affect the viability of the cells (see Figure 1), it moderately blocked the formation of the colonies. This may be due to the drugs' negative effect on cell cycle progression (Hannun, 1997; Los et al, 1997), which inhibits the cells from forming colonies. The high dose of Dox treatment $\left(5 \mu \mathrm{g} \mathrm{ml}^{-1}\right)$ completely prevented the cells from forming colonies. The combination treatment of the low
Table I Colony formation of LNCaP cells in soft agar

\begin{tabular}{lcc}
\hline Treatment & No. of colonies & s.d. \\
\hline No treatment & 174 & \pm 7.5 \\
PL $\left(0.5 \mu \mathrm{g} \mathrm{ml}^{-1}\right)$ & 87 & \pm 5 \\
Dox $\left(1.0 \mu \mathrm{g} \mathrm{ml}^{-1}\right)$ & 65 & \pm 0.2 \\
Dox $\left(5.0 \mu \mathrm{g} \mathrm{ml}^{-1}\right)$ & 0 & \pm 0.8 \\
PL $\left(0.5 \mu \mathrm{g} \mathrm{ml}^{-1}\right)+$ Dox $\left(\mid \mu \mathrm{g} \mathrm{ml}^{-1}\right)$ & 4 & \pm 0.5 \\
\hline
\end{tabular}

Dox = doxorubicin; $\mathrm{PL}=$ Phellinus linteus. The cells were cultured in soft agar in the presence of PL, Dox, or the combination of PL and Dox for 2 weeks. s.d.: standard deviation over five independent experiments.

doses of PL and Dox achieved a prominent blocking effect on colony formation. Thus, the data suggest the existence of a synergistic, cytotoxic effect of PL and Dox, at low doses, on prostate cancer cells.

\section{Involvement of caspases in the synergistic effect of PL and Dox}

The caspase cascade plays an important role in many types of apoptosis, including Dox-induced apoptosis (Hannun, 1997; Los et al, 1997). It is known that Dox, at high doses, can induce apoptosis, possibly through caspase-mediated apoptotic signalling, including caspase 8 (Hannun, 1997; Los et al, 1997). To determine whether and which caspases are involved in the synergistic induction of apoptosis by PL and Dox, our primary focus was to study the mechanisms of the combination treatment of PL and Dox on several caspase family members. Caspases, upon activation, are cleaved into a small, active form (Hannun, 1997; Los et al, 1997). Therefore, immunoblot analysis was employed using caspases 3,8 and BID antibodies to detect the presence and levels of the corresponding proteins following various treatments (Figure 2A). The active, cleaved forms of caspases 3, 8 and BID were absent in LNCaP cells upon treatment with low doses of PL or Dox. In comparison, the caspases were significantly activated in response to the combination treatment. To further determine the activation of caspases by the co-treatment of PL and Dox, the activities of caspases 3 and 8 were measured using an enzymatic assay (Figure 2B). Again, the activities of these proteases were undetectable following treatment with low doses of PL or Dox alone. The combination treatment dramatically upregulated the activities of these caspases.

Cytochrome $c$ is an apoptotic executor during the process of caspase-mediated apoptosis. Therefore, the release of cytochrome $c$ from the mitochondria to the cytosol in response to various treatments was also examined in LNCaP cells (Figure 3). After isolating the cytosolic or mitochondrial fractions from untreated or treated LNCaP cells, immunoblotting was performed using an anti-cytochrome $c$ antibody. Cyctochrome $c$ was present in the cytosolic fraction isolated from the cells treated with the combination of PL and Dox, but not in the cells either untreated or treated with PL or Dox alone (Figure 3, upper panel). Also, after the addition of low doses of PL plus Dox, the anti-cytochrome $c$ antibody could not detect the protein in the mitochondrial fraction of the cells, but the protein was present in the mitochondrial fraction of either untreated cells or cells treated with PL or Dox (Figure 3, lower pannel). Overall, these results indicate that low doses of PL and Dox can synergise to enhance caspase activity in LNCaP cells.

\section{JNK is activated and controls FLIP $_{\mathrm{L}}$ expression in response to PL or PL plus Dox}

JNK, a stress-related kinase, requires phosphorylation to be activated and is often involved in the modulation of various types 

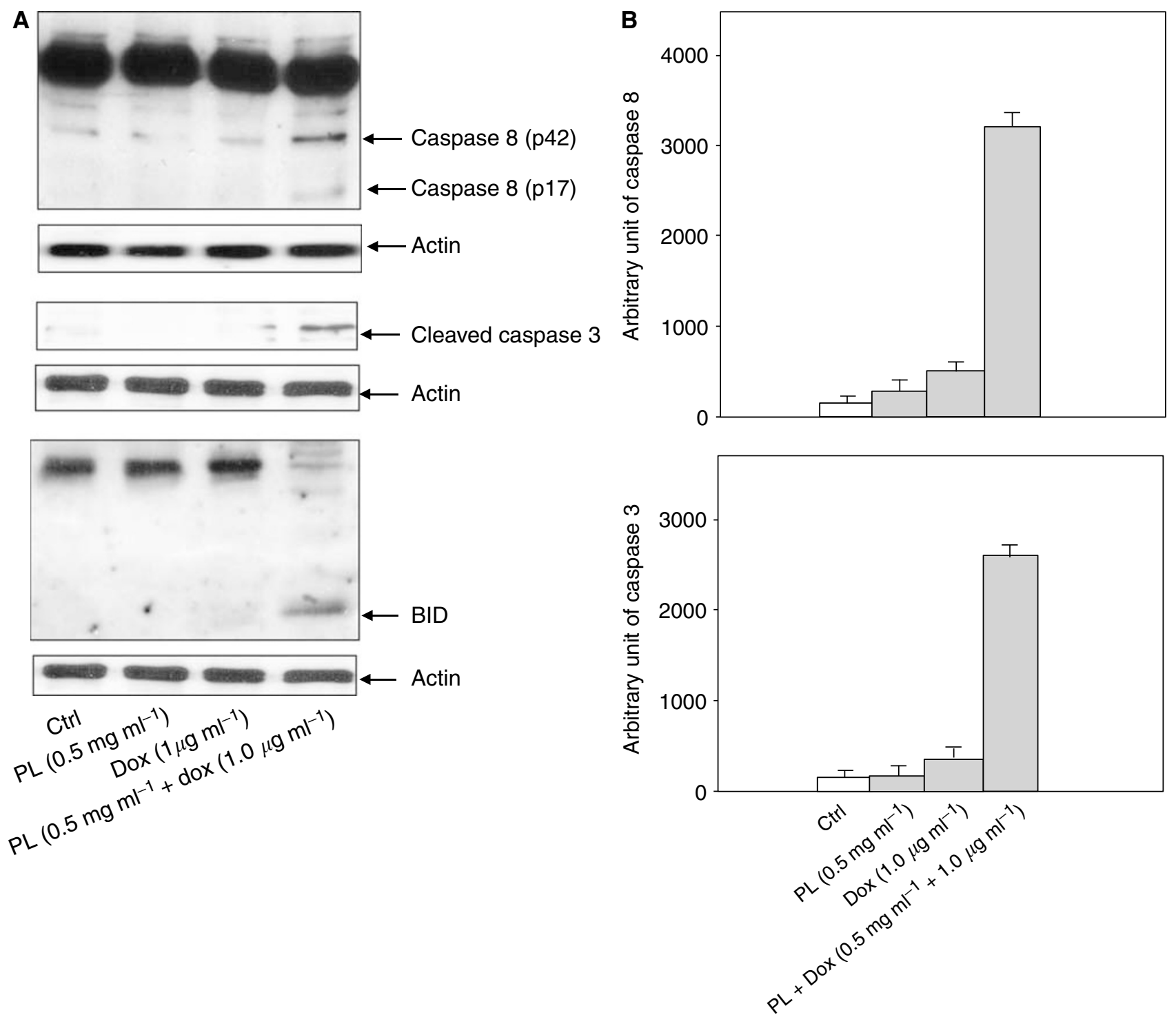

Figure 2 Activation of caspase 3, 8 or BID following the treatmet with PL, Dox or PL plus Dox. (A) After treating with PL, Dox, or PL plus Dox, LNCaP cells were harvested and lysates were prepared. The existence of activated forms of caspases 3, 8 and BID was determined by Western blot. Equal loading of total proteins was verified by $\beta$-Actin expression. (B) Following the treatments, lysates were prepared to measure the activity of these caspase family members using a colorimetric assay. Error bars represent the s.d. over five independent experiments.

of apoptosis, including those induced by caspases (Davis, 2000). It has been shown that JNK activation in tumour necrosis factor (TNF) $\alpha$-induced apoptotic processes promotes the activity of caspases by regulating the expression level of c-FLIP $\mathrm{L}_{\mathrm{L}}$, a caspase cascade inhibitor (Chang et al, 2006). To determine the JNK activation status in our experimental settings, the expression of JNK was analysed by immunoblotting using an anti-JNK antibody. JNK protein expression was detectable in untreated LNCaP cells or cells treated with Dox (Figure 4A, upper panel). In comparison, PL treatment alone or the combination treatment augmented the expression of this kinase. As JNK is phosphorylated upon activation, its phosphorylation status was then determined using the anti-phos-JNK antibody (Figure 4A, lower panel). The phosphorylated JNK was recognised by the antibody in the cells treated with PL alone or co-treated with PL plus Dox. JNK was not activated by the addition of Dox alone.

JNK has been demonstrated to regulate the degradation of cFLIP $_{\mathrm{L}}$ that is an important negative regulator of caspase 8 and further controls the expression of the protein (Chang et al, 2006).
We conducted immunoblotting experiments to test the expression of c-FLIP $\mathrm{L}_{\mathrm{L}}$ in LNCaP cells (Figure 4B). The amount of $\mathrm{c}$-FLIP expression in the cells treated with Dox alone was the same as that in untreated cells. However, c-FLIP $\mathrm{L}_{\mathrm{L}}$ expression was dramatically suppressed by PL or the combination treatment. In addition, blockade of JNK expression by introduction of a dominantnegative $J N K$ into the cells lifted the inhibitory effect on the expression of c-FLIP ${ }_{\mathrm{L}}$ rendered by the treatment with PL or PL plus Dox. The data suggest that PL, via regulating JNK activation and subsequent c-FLIP $\mathrm{L}_{\mathrm{L}}$ expression, synergises with Dox for the initiation of a caspase cascade.

To further determine the nature of the synergistic effect of PL on Dox-induced apoptosis, a DNA fragmentation assay was conducted in the presence of caspase or JNK inhibitors (Figure 5). A general caspase inhibitor z-VADfmk completely blocked the apoptotic process induced by the co-treatment with PL and Dox. Furthermore, the magnitude of apoptosis elicited by the combination treatment was significantly suppressed by the addition of a JNK inhibitor or the introduction of a $d n-J N K$ into LNCaP cells, 


\section{Cytosol}

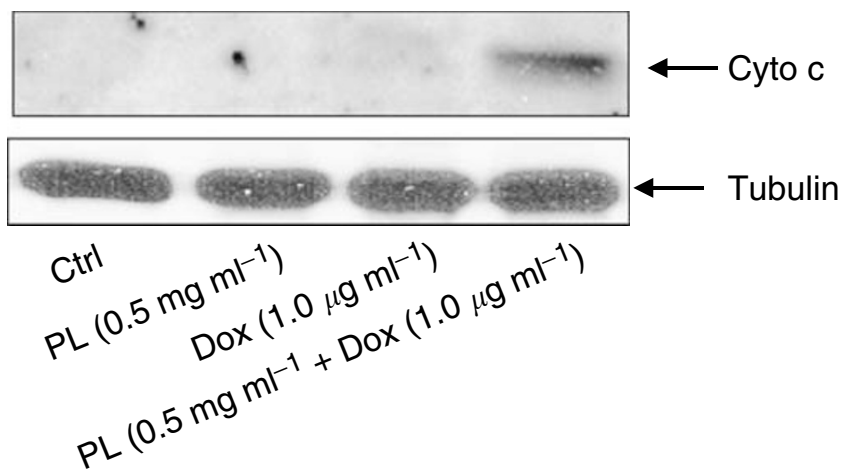

Mitochondria

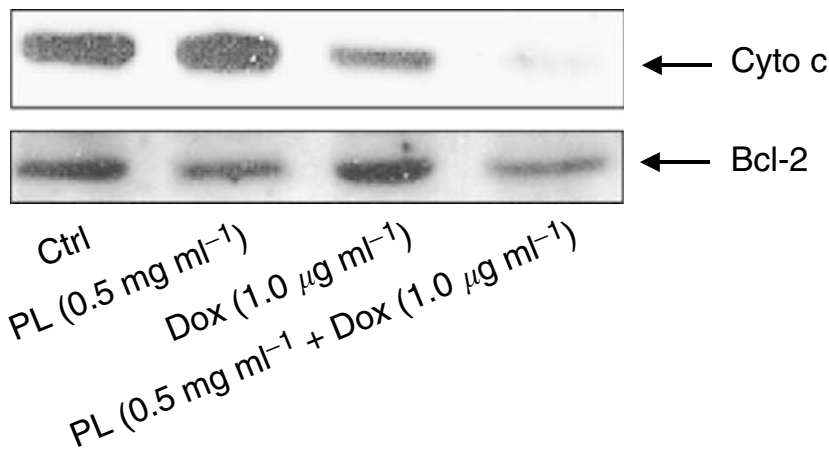

Figure 3 Releasing of cytochrome $c$ to the cytosol following the treatment with PL, Dox, or PL plus Dox. The mitochondrial or cytosolic fractions from untreated or treated cells were isolated and analysed for the expression of cytochrome c by Western blot. Equal loading of proteins in the mitochondrial or cytosolic fraction was determined by reprobing the blot with antitubulin or $\mathrm{Bcl}-2 \mathrm{Ab}$.

which again supports the notion that PL, via activating JNK and further blocking c-FLIP ${ }_{\mathrm{L}}$, potentiates Dox-induced apoptosis.

\section{DISCUSSION}

In the apoptotic process induced by the co-treatment of PL and Dox, caspase 8 is activated, which then initiates a caspase cascade, resulting in the release of cytochrome $c$ from the mitochondria to the cytosol. The suppression of caspase activity by a generic caspase inhibitor z-VADfmk completely abolishes apoptosis induced by the co-treatment. Furthermore, the addition of PL alone is able to cause JNK activation, which subsequently downregulates the expression level of $c-\mathrm{FLIP}_{\mathrm{L}}$ in the cells. The addition of a JNK inhibitor or introduction of a $d n$-JNK suppresses the apoptotic process induced by the co-treatment. Therefore, our findings suggest that PL is a useful synergiser for augmenting Doxmediated, apoptotic signalling. As such synergy on the induction of apoptosis only requires low doses of Dox, PL has potential for further developing a better therapeutic strategy to treat prostate cancer and avoid the side effects caused by high doses of Dox.

Because prostate cancer progression is partially affected by development of resistance of the cancer cells to apoptosis induced by anticancer drugs, the ability to sensitise apoptotic signalling pathways has important therapeutic implications. Genetic targeting or pharmacological manipulation of caspase family members and their regulators/modulators would provide better clinical strategies. Targeting the expression of caspase 7 has been demonstrated to be a useful approach for treating prostate cancer
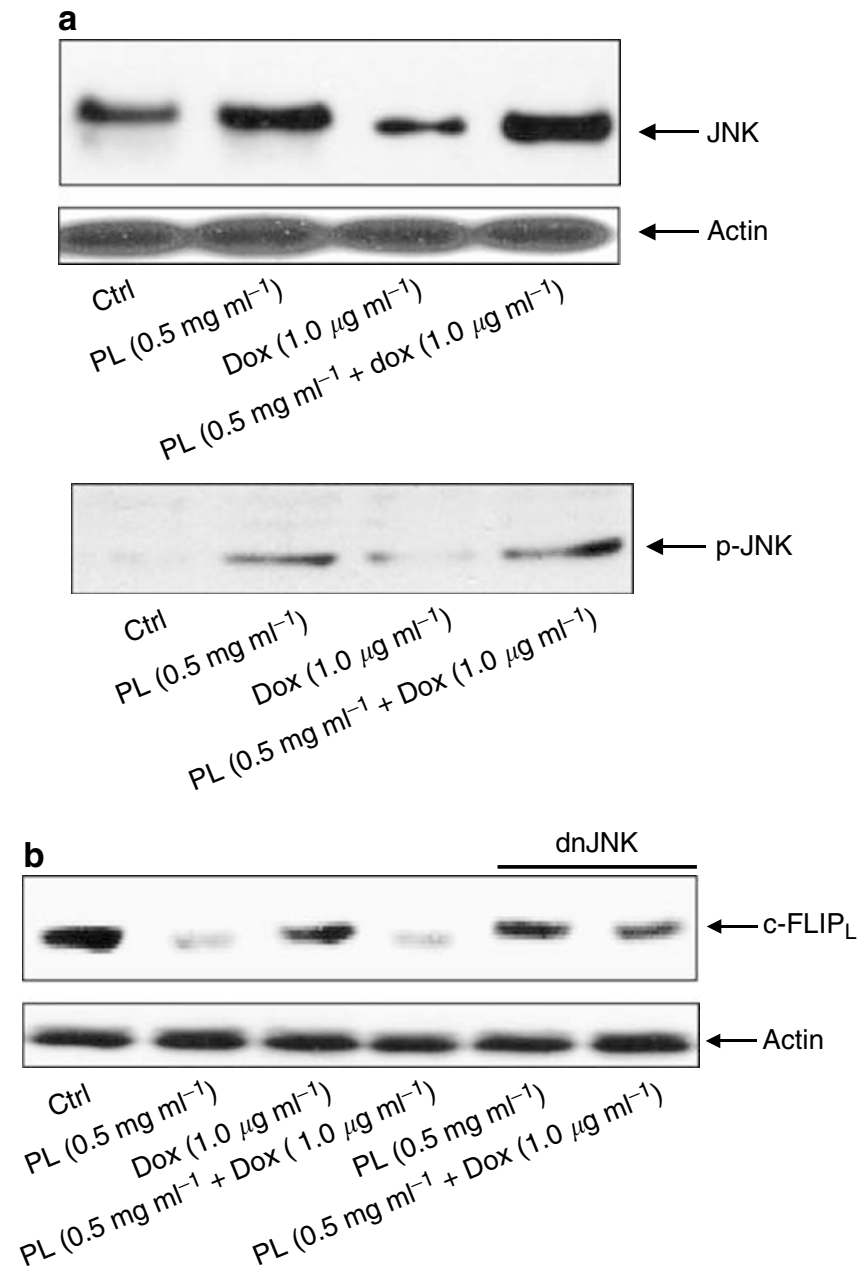

Figure 4 JNK activation and $c$-FLIP $P_{L}$ expression. (A) After treatment with PL, Dox or PL plus Dox, cells were harvested and lysates were prepared. The protein expression level of JNK or the presence of the phosphorylated form of JNK was determined by Western blot using the corresponding antibodies. Equal loading of total proteins in each sample was verified by $\beta$-actin. (B) $\mathrm{C}$-FLIP $\mathrm{L}$ expression upon treatment with $\mathrm{PL}$, Dox, or PL plus Dox. The cells with or without addition of a $d n-J N K$ were treated with PL, Dox, or PL plus Dox. Subsequently, lysates were prepared to analyse the expression level of c-FLIP $P_{L}$. The percentages of the cells with fragmented DNA were determined by flow cytometry. The error bars represent the s.d. over five independent experiments.

(Marcelli et al, 1998, 1999). In this approach, overexpression of caspase 7 in LNCaP cells could effectively induce apoptosis and has been shown to be very promising clinically (Marcelli et al, 1998, 1999). Therefore, the combination treatment of low doses of PL and Dox to activate caspases would have similar implications for treating prostate cancer patients.

Studies using specific caspase inhibitors have shown that Dox can activate caspases 8, 6 and 3 (Hannun, 1997; Los et al, 1997). The synergistic effect of Dox and TRAIL on caspase-induced apoptosis has been reported (Wu et al, 2002). Here, we demonstrated that Dox is also able to synergise with PL at low doses for the induction of apoptosis. In this apoptotic process, caspases 3, 8 and BID are activated, leading to the release of cytochrome $c$ from the mitochondria to the cytosol. A generic caspase inhibitor blocked this synergistic, apoptotic effect on LNCaP cells, further suggesting the involvement of caspase activity in the cytotoxicity rendered by the combination treatment with PL and Dox. However, at low doses neither Dox nor PL elicited the 


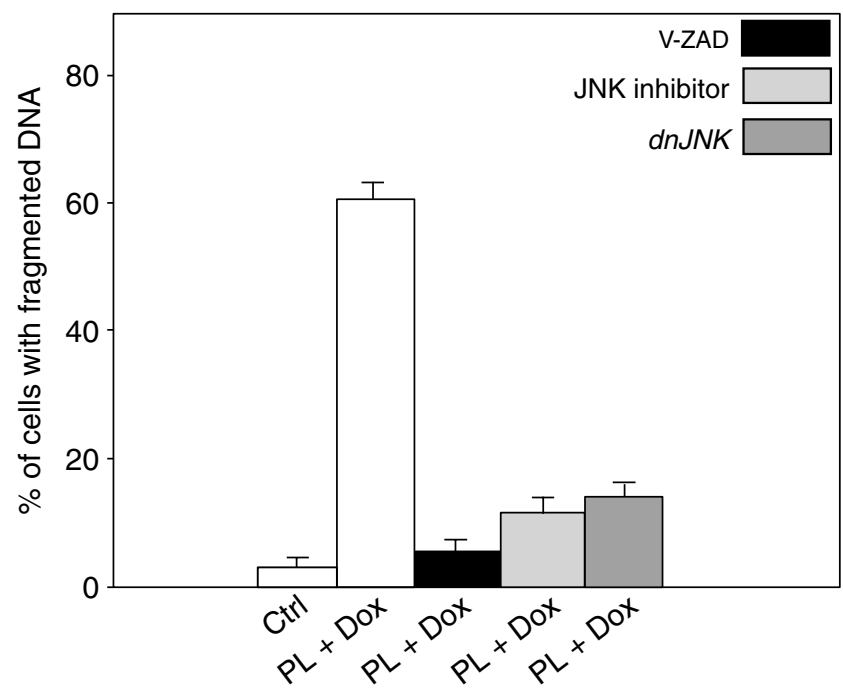

Figure $\mathbf{5}$ Effect of JNK inhibition on apoptosis induced by the combination treatment. After introducing a dn-/NK or treatment with a JNK inhibitor, the percentages of DNA fragmentation in LNCaP cells with or without treatment with PL plus Dox were analysed by a flow cytometer. Error bars represent the s.d. over five independent experiments.

activity of these caspase family members to induce apoptosis. It is possible that treatment with PL at low doses reduces the threshold of the sensitivity of LNCaP cells to Dox-induced apoptosis.

JNK is activated in response to various stresses. The exact mechanisms through which JNK participates in apoptosis remain unknown. JNK is not a direct apoptotic executor, however, instead, it often modulates the initiation of apoptosis through promoting processing of proapoptotic factors, such as the BH3-domain proteins or decaying of antiapoptotic factors (Luo et al, 1998). In caspase-induced apoptosis, JNK has been suggested to act at a step upstream to caspase 8 (Deng et al, 2003). Recently, experiments, in vitro and in vivo, have shown that JNK, during TNF $\alpha$-induced apoptotic processes, activates ubiquitin ligase Itch, which specifically interacts with $\mathrm{c}^{\mathrm{FLIP}} \mathrm{L}$ to promote the degradation of this caspase inhibitor (Chang et al, 2006). In our experimental settings, a low dose of PL was enough to elicit JNK phosphorylation, but not to induce apoptosis. However, this activation of JNK was responsible for the reduction of $c-$ FLIP $_{L}$ expression in LNCaP cells. Therefore, JNK, by promoting the degradation process, suppresses c-FLIP ${ }_{\mathrm{L}}$, and may sensitise the prostate cancer cells to apoptosis. Doxorubicin is known to be able to elicit cellular or DNA damage-induced responses at low-dose ranges and mobilise caspase family members to execute cell death programs at highdose ranges. It is well possible that JNK, by lowering the threshold of LNCaP cells to apoptosis, synergises with Dox for the activation of caspases.

Phellinus linteus and Dox, at low doses, are $\mathrm{G}_{1}$ arrest inducers (Guo et al, 2006). The data from colony formation assays demonstrated that LNCaP cells formed fewer colonies in soft agar medium in the presence of a low dose of Dox or PL alone. In contrast, the combination treatment with these two agents at low doses blocks LNCaP cells from growing and forming colonies in soft agar medium. The reduction of the numbers of colonies following treatment with Dox or PL alone at low concentrations is highly likely due to a negative effect of the treatment on cell proliferation, resulting in slow formation of colonies. In addition, the combination treatment of low doses of PL and Dox is nontoxic to normal prostate epithelial cells, causing only growth cessation. This suggests that PL can selectively sensitise cancer cells for apoptotic signalling.

The development of chemotherapeutic resistance to drugs is a major obstacle to the successful treatment of prostate cancer. A more effective anticancer therapy is required. Our present study demonstrates that PL acts as an enhancer to sensitise Doxmediated, apoptotic signalling, and this sensitisation can be obtained at subtoxic concentrations of Dox. We previously have reported that PL, even at high doses, only causes normal fibroblasts or lung epithelial cells to arrest in the $G_{1}$ phase of the cell cycle (Guo et al, 2006). Altogether, our data suggest that PL is an apoptotic synergiser for conventional chemotherapeutics such as Dox, which can keep normal, surrounding cells unharmed. Therefore, PL, serving as a safe alternative medicine, has potential for more efficient therapies against drug-resistant prostate cancer.

\section{ACKNOWLEDGEMENTS}

We thank Dr Sun (Kyunghee University, South Korea) and Dr Dong (University of Minnesota, Austin) for their expertise on PL study.

\section{REFERENCES}

Alnemri ES, Livingston DJ, Nicholson DW, Salvesen G, Thomberry NA, Wong WW, Yuan J (1996) Human ICE/CED-3 protease nomenclature. Cell 87: $171-179$

Borchers AT, Stern JS, Hackman RM, Keen CL, Gershwin EM (1999) Minireview: mushrooms, tumors and immunity. Soc Exp Biol Med 221: $281-293$

Chang L, Kamata H, Solinas G, Luo J, Maeda S, Venuprasad K, Liu Y, Karin M (2006) The E3 ubiquiting ligase Itch couples JNK activation to TNF $\alpha$ induced cell death by inducing c-FLIP ${ }_{\mathrm{L}}$ Turnover. Cell 124: $601-613$

Chihara G, Maeda Y, Hamuro J, Sasaki T, Fumiko F (1969) Inhibition of mouse sarcoma 180 by polysaccharides from Lentinus edodes. Nature 222: $687-688$

Chung KS, Choi EC, Kim BK, Kim YS, Park YK (1982) The constituents and culture of Korean Basidiomycetes: antitumor polysaccharides from the cultured mycelia of some Basidiomycetes. Arch Pharm Res 5: 17-20

Cohen GM (1997) Caspases: the executioners of apoptosis. Biochem J 326: $1-16$

Cun Z, Mizuno T, Ito H, Shimura K, Sumiya T, Kawade M (1994) Antitumor activity and immunological property of polysaccharides from the mycelium of liquid-cultured Grifola frondosa. J Jpn Soc Food Sci Technol 41: $724-732$

Davis RJ (2000) Signa transduction by the JNK group of MAP kinases. Cell 103: $239-252$

Deng Y, Ren X, Yang L, Lin Y, Wu X (2003) A JNK-dependent pathway is required for TNFalpha-induced apoptosis. Cell 115: $61-70$

Denis GV, Yu Q, Ma P, Deeds L, Faller DV, Chen C-Y (2003) Bcl-2, via its BH4 domain, blocks apoptotic signaling mediated by mitochondrial Ras. J Biol Chem 278: 5775-5785

Derijard B, Hibi M, Wu I, Barrett T, Su B, Deng T, Karin M, Davis RJ (1994) JNK1: a protein kinase stimulated by UV light and Ha-Ras that binds and phosphorylates the c-Jun activation domain. Cell 76: 1025-1037

Devary Y, Gottieb RA, Lau LF, Karin M (1991) Rapid and preferential activation of the c-Jun gene during the mammalian UV response. $\mathrm{Mol}$ Cell Biol 11: 2804-2811

Gao M, Labuda T, Xia Y, Gallagher E, Fang D, Liu Y, Karin M (2004) Jun turnover is controlled through JNK-dependent phosphorylation of the E3 ligase Itch. Science 306: $271-275$

Guo J, Zhu T, Collins L, Xiao ZJ, Chen C-Y (2006) Modulation of lung cancer growth arrest and apoptosis by Phellinus Linteus. (in press)

Han SB, Lee CW, Jeon YJ, Hong ND, Yoo ID, Yang K-H, Kim HM (1999) The inhibitory effect of polysaccharide isolated from Phellinus linteus on tumor growth and metastasis. Immunopharm 41: 157-164 
Hannun YA (1997) Apoptosis and the dilemma of cancerchemotherapy. Blood 89: $1845-1853$

Hibi M, Lin A, Smeal T, Minden A, Karin M (1993) Identification of an oncoprotein- and UV-responsive protein kinase that bind and potentiate the c-Jun activation domain. Genes Dev 7: 51-59

Keane MM, Ettenberg SA, Nau MM, Russell EK, Lipkowitz S (1999) Chemotherapy augments TRAIL-induced apoptosis in breast cell lines. Cancer Res 59: 734-741

Lacour S, Hammann A, Wotawa A, Corcos L, Solary E, Dimanche-Boitrel MT (2001) Anticancer agents sensitize tumor cells to tumor necrosis factor-related apoptosis-inducing ligand-mediated caspase- 8 activation and apoptosis. Cancer Res 61: $1645-1651$

Lorenzen K, Anke T (1998) Biologically active metabolites from basidiomycetes. Curr Org Chem 2: 329-364

Los M, Herr I, Friesen C, Fulda S, Schulze-Osthoff K, Lipkowitz S (1997) Cross-resistance of CD95 and drug-induced apoptosis as a consequence of deficient activation of caspases (ICE/Ced-3 proteases). Blood 90: $3118-3129$

Luo X, Budihardjo I, Zou H, Slaughter C, Wang X (1998) Bid, a Bcl-2 interacting protein, mediates cytochrome $c$ release from mitochondria in response to activation of cell surface death receptors. Cell 94: 481-490

Marcelli M, Cunningham GR, Haidacher SJ, Padayatty SJ, Sturgis L, Kagan C, Denner L (1998) Caspase-7 is activated during lovastatin-induced apoptosis of the prostate cancer cell line LNCaP. Cancer Res 58: 76-83

Marcelli M, Cunningham GR, Walkup M (1999) Signaling pathway activated during apoptosis of the prostate cancer cell line LNCaP: overexpression of caspase-7 as a new gene therapy strategy for prostate cancer. Cancer Res 59: $382-390$
Muzutani Y, Yoshida O, Miki T, Bonavida B (1999) Synergistic cytotoxicity and apoptosis by Apo-2 ligand and adriamycin against bladder cancer cells. Clin Cancer Res 5: 2605-2612

Nicholson DW, Thomberry NA (1997) Caspases: killer proteases. Trends Biochem Sci 22: 299-306

Oh GT, Han SB, Kim HM, Han MW, Yoo ID (1992) Immunostimulating activity of Phellinus linteus extracts to B-lymphocyte. Arch Pharm Res 15: $379-381$

Reshetnikov SV, Wasser SP, Tan KK (2001) Higher Basidiomycetes as a source of antitumour and immunostimulating polysaccharides (Review). Int J Med Mushrooms 3: $361-394$

Salvesen GS, Dixit VM (1997) Caspases: intracellular signaling by proteolysis. Cell 91: $443-446$

Song KS, Cho SM, Lee IK, Kim HM, Han SB, Ko KS, Yoo ID (1995) B-lymphocyte-stimulating polysaccharide from mushroom Phellinus linteus. Chem Pharm Bull 43: 2105-2108

Wasser SP (2002) Medicinal mushrooms as a source of antitumor and immunomodulating polysaccharides. Appl Microbiol Biotech 60 $258-274$

Wu X, Kakehi Y, Mizutani Y, Kamoto T, Kinoshita H, Isogawa Y, Terachi T, Ogawa O (2002) Doxorubicin enhances TRAIL-induced apoptosis in prostate cancer. Int J Oncol 20: $949-954$

Wu X, Kakehi Y, Mizutani Y, Lu JJ, Terachi T, Ogawa O (2001) Activation of caspase 3 in renal cell carcinoma cells by anthracyclines or 5-fluorouracil. Int J Oncol 19: 19-24

Yamanaka T, Shiraki K, Sugimoto K (2000) Chemotherapeutic agents augment TRAIL-induced apoptosis in human hepatocellular carcinoma cell lines. Hepatology 32: $482-490$ 